\title{
Correction of irregular and induced regular corneal astigmatism with toric IOL after posterior segment surgery: a case series
}

\author{
Bence L. Kolozsvári, Gergely Losonczy, Dorottya Pásztor and Mariann Fodor * (i)
}

\begin{abstract}
Background: Toric intraocular lens ( $\mathrm{IOL})$ implantation can be an effective method for correcting corneal astigmatism in patients with vitreoretinal diseases and cataract. Our purpose is to report the outcome of toric IOL implantation in two cases - a patient with scleral-buckle-induced regular corneal astigmatism and a patient with keratoconus following pars plana vitrectomy. As far as we are aware, there are no reported cases of toric $\mathrm{IOL}$ implantation in a vitrectomized eye with keratoconus nor of toric IOL implantation in patients with scleral-buckle-induced regular corneal astigmatism.

Case presentation: Two patients with myopia and high corneal astigmatism underwent cataract operation with toric IOL implantation after posterior segment surgery. Myopia and high astigmatism ( $>2.5$ diopter) were caused by previous scleral buckling in one case and by keratoconus in the other case. Pre- and postoperative examinations during the follow-up of included uncorrected and spectacle corrected distance visual acuity (UCDVA/CDVA), automated kerato-refractometry (Topcon), Pentacam HR, IOL Master (Zeiss) axial length measurements and fundus optical coherence tomography (Zeiss). One year postoperatively, the UCDVA and CDVA were 20/25 and 20/20 in both cases, respectively. The absolute residual refractive astigmatism was 1.0 and 0.75 Diopters, respectively.

The IOL rotation was within $3^{\circ}$ in both eyes, therefore IOL repositioning was not necessary. Complications were not observed in our cases.

Conclusion: These cases demonstrate that toric IOL implantation is a predictable and safe method for the correction of high corneal astigmatism in complicated cases with different origins. Irregular corneal astigmatism in keratoconus or scleral-buckle-induced regular astigmatisms can be equally well corrected with the use of toric IOL during cataract surgery. Previous scleral buckling or pars plana vitrectomy seem to have no impact on the success of the toric IOL implantation, even in keratoconus. IOL rotational stability and refractive predictability in patients with a previous vitreoretinal surgery can be as good as in uncomplicated cases.
\end{abstract}

Keywords: Toric IOL, Scleral buckling, Keratoconus, Vitrectomy

\section{Background}

Cataract surgery is one of the most frequent surgeries worldwide. With the improvement of biometry procedures, including corneal topography and tomography, toric intraocular lens (IOL) implantation has become more and more predictable in correcting astigmatism [1-3].

The improvement in vitreoretinal surgical techniques has enabled eye surgeons to manage more challenging

\footnotetext{
* Correspondence: mfodor@med.unideb.hu

Department of Ophthalmology, Faculty of Medicine, University of Debrecen, Nagyerdei krt. 98, H-4012 Debrecen, Hungary
}

cases. However, vision rehabilitation can be cumbersome in patients with multiple refractive comorbidities. Toric IOL implantation can be an effective method for correcting corneal astigmatism in patients with vitreoretinal diseases and cataract. This is because toric IOLs show good rotational stability, even in vitrectomized eyes [2]. Cataract surgery with the implantation of toric IOL in stable keratoconus is a safe and effective procedure regarding keratometry stability, visual and refractive results [3-5]. As far as we are aware, there is no reported case of toric IOL implantation in a vitrectomized eye with keratoconus. 
Scleral buckling is a great surgical procedure to treat rhegmatogenous retinal detachment but can induce permanent changes in the anatomy of both the anterior and posterior segments. As a result, myopic shift and high astigmatism frequently occur [6-8]. A unilateral difference in refraction creates anisometropia, and the correction with spectacle may be impossible. Different types of corneal laser refractive surgeries and phakic intraocular lenses implantations have been proved to be safe and predictable methods for reducing these refractive errors [6-8]. If cataract surgery is indicated, phacoemulsification with toric IOL implantation might give an opportunity to retain visual balance and may reverse the refractive status. To the best of our knowledge, no cases of toric IOL implantation in patients with scleral-buckle-induced regular corneal astigmatism have been reported before.

The purpose of this case series was to evaluate the longterm outcome of toric IOL implantation in a patient with irregular cornea astigmatism due to keratoconus following a pars plana vitrectomy and in a different patient with regular corneal astigmatism, caused by a previous scleral buckling procedure.

\section{Case presentation}

This noncomparative, interventional case series was performed at a single center (Department of Ophthalmology, University of Debrecen) and all of the surgeries were performed by the same surgeon (M.F.). We enrolled two female patients with previous posterior segment surgeries and a postoperative corneal astigmatism that was greater than 2.5 diopters (D). In case 1 , an encircling buckle and a radial sponge were placed to treat a rhegmatogenous retinal detachment. In case 2, a patient with keratoconus developed a vitreous hemorrhage, which was caused by a branch retinal artery occlusion. This was managed with 23-gauge vitrectomy. After these primary standard operations, the patients developed cataract, associated with myopia and high astigmatism.

In case 1, a previous scleral buckling procedure induced high regular corneal astigmatism. In accordance with the 70-year-old patient, we did not remove the encircling buckle or the radial sponge and neither did we choose excimer laser to treat the corneal astigmatism. Instead, to reduce the chance of possible complications, we chose cataract surgery and toric IOL implantation. This addressed both the cataract and high corneal astigmatism in a single session. In case 2 , the cause of refractive error was a stage 1 keratoconus (based on Amsler-Krumeich Classification) stable for many years, as shown by Pentacam examinations. Cataract surgery with toric IOL implantation was offered for the 55-year-old patient, irrespective of the previous vitrectomy. Following a comprehensive discussion of the toric IOL implantation and potential risks, both of the patients gave written consent.
A complete ophthalmological and medical history was achieved from both of the patients.

Both eyes underwent a standard phacoemulsification and toric IOL (case 1: +17.5D AcrySof Toric SN6AT7, case 2: +15.0 D AcrySof Toric SN6AT6) implantation using Infinity Vision System (Alcon Laboratories) through a $2.6 \mathrm{~mm}$ corneal incision. The preoperative and postoperative evaluations included an assessment of the uncorrected distance visual acuity (UCDVA), spectacle corrected distance visual acuity (CDVA), automated kerato-refractometry (KR-8900; Topcon Co, Tokyo, Japan), slitlamp biomicroscopy, indirect ophthalmoscopy and applanation tonometry. Both of the patients had Rotating Scheimpflug tomography (Pentacam HR, Oculus Optikgeräte GmbH, Wetzlar, Germany) and IOL Master (Carl Zeiss Meditec, Jena, Germany) before the toric IOL implantation and during the 12-month follow-up. Fundus OCT was used to exclude any fundus anomalies (i.e., astigmatism) in case 1.

The IOL powers were calculated using the SRK/T formula, and the targeted refraction was emmetropia. The IOL cylinder power and alignment axis were calculated using the web-based toric IOL calculator program (available at: www.acrysoftoriccalculator.com). The final IOL diopters were determined based on keratometry readings (kerato-refractometry, Pentacam HR, IOL Master) and axial length measurements (IOL Master). The position of the cylindrical axis of the IOL was preoperatively marked in a sitting position and postoperatively measured using a slit lamp (Haag-Streit, BC 900, Switzerland) with a thin coaxial rotated slit light.

The clinical data of the patients are summarized in Table 1. No patients had intraoperative or postoperative complications. The fundus OCT showed normal macular anatomy and no fundus astigmatism in case 1 . No patients developed retinal detachment or vitreoretinal changes in the treated eye during the 12-month follow-up.

One year after the toric IOL implantation, the UCDVA was above 20/25 and the CDVA was 20/20 in both cases. The absolute residual refractive cylinders were 1.0 and 0.75 Diopters. The IOL rotational misalignment was within $3^{\circ}$ in both eyes. No eyes required further IOL repositioning. Taken together, a significant improvement in CDVA and UCDVA was observed in both cases. Refraction was stable during the follow-up period (Table 1). Both of the patients were satisfied with their postoperative visual outcome.

\section{Conclusion}

There are many surgical options for treating preexisting or induced corneal astigmatism including excimer laser refractive procedures, limbal or corneal relaxing incisions and phakic IOLs. All of these treatments have limitations including the degree of treatable astigmatism and longterm instability [1]. In the present paper, we report the successful management of two cases with cataract and 
Table 1 Clinical data of patients along with the IOL design performed with 3 different devices

\begin{tabular}{|c|c|c|}
\hline & Patient 1. & Patient 2. \\
\hline \multicolumn{3}{|l|}{ Preoperative clinical data } \\
\hline $\begin{array}{l}\text { Vitreoretinal procedure; } \\
\text { date of intervention; age at the operation }\end{array}$ & $\begin{array}{l}\text { scleral buckling on the right eye } \\
\text { (encircling buckle and a radial sponge); } \\
\text { September 2011; } 67 \text { years old }\end{array}$ & $\begin{array}{l}\text { 23-gauge vitrectomy on the left eye; } \\
\text { December 2013; } 54 \text { years old }\end{array}$ \\
\hline Cause of refractive errors & scleral buckling implants (Figs. 1 and 2) & Keratoconus \\
\hline UCDVA & $20 / 200$ & $20 / 500$ \\
\hline CDVA & $20 / 50$ with $-6.0+4.5 \times 20$ degrees & $20 / 50$ with $-10.5+4.0 \times 15$ degrees \\
\hline \multicolumn{3}{|l|}{ Preoperative measurements and $\mathrm{IOL}$ design } \\
\hline Topcon KR8100 keratorefractometer & $\begin{array}{l}\text { K1: } 42.75 \mathrm{D} / 125^{\circ} \\
\text { K2: } 46.25 \mathrm{D} / 35^{\circ} \\
\text { Calculated IOL type: AcrySof Toric T7 }\end{array}$ & $\begin{array}{l}\text { K1: } 48.25 \mathrm{D} / 40^{\circ} \\
\text { K2: } 50.75 \mathrm{D} / 130^{\circ} \\
\text { Calculated IOL type: AcrySof Toric T6 }\end{array}$ \\
\hline Pentacam HR & $\begin{array}{l}\text { K1: } 42.1 \mathrm{D} / 129^{\circ} \\
\text { K2:45.3D /39 (Fig. 1) } \\
\text { Calculated IOL type: AcrySof Toric T7 }\end{array}$ & $\begin{array}{l}\text { K1: } 48.0 \mathrm{D} / 45^{\circ} \\
\text { K2: } 50.2 \mathrm{D} / 135^{\circ} \\
\text { Calculated IOL type: AcrySof Toric T6 }\end{array}$ \\
\hline Zeiss IOL Master & $\begin{array}{l}\text { K1: 43.05D / } 127^{\circ} \\
\text { K2: } 45.98 \text { D / } 37^{\circ} \\
\text { Calculated IOL type: AcrySof Toric T6 }\end{array}$ & $\begin{array}{l}\text { K1: } 47.87 \mathrm{D} / 46^{\circ} \\
\text { K2: } 50.60 \mathrm{D} / 136^{\circ} \\
\text { Calculated IOL type: AcrySof Toric T6 }\end{array}$ \\
\hline $\begin{array}{l}\text { Axial length }(\mathrm{mm}) \\
\text { Zeiss IOL Master }\end{array}$ & $24.47 \mathrm{~mm}$ & $23.92 \mathrm{~mm}$ \\
\hline Implanted toric $\mathrm{IOL}$ & +17.5D AcrySof Toric SN6AT7 & +15.0 D AcrySof Toric SN6AT6 \\
\hline Axis of $\mathrm{IOL}$ positioning & $35^{\circ}$ & $44^{\circ}$ \\
\hline Time of phacoemulsification & February 2014 & June 2014 \\
\hline \multicolumn{3}{|l|}{ Postoperative measurements at 1 month } \\
\hline Topcon KR8100 keratorefractometer & $\begin{array}{l}\mathrm{K} 1: 42.25 \mathrm{D} 125^{\circ} \\
\mathrm{K} 2: 46.25 \mathrm{D} 35^{\circ}\end{array}$ & $\begin{array}{l}\mathrm{K} 1: 47.5 \mathrm{D} 30^{\circ} \\
\mathrm{K} 2: 50.75 \mathrm{D} 120^{\circ}\end{array}$ \\
\hline Pentacam HR & $\begin{array}{l}\mathrm{K} 1: 41.6 \mathrm{D} 136^{\circ} \\
\mathrm{K} 2: 45.5 \mathrm{D} 46^{\circ}\end{array}$ & $\begin{array}{l}\mathrm{K} 1: 47.4 \mathrm{D} 37^{\circ} \\
\mathrm{K} 2: 50.0 \mathrm{D} 127^{\circ}\end{array}$ \\
\hline UCDVA & $20 / 25$ & $20 / 30$ \\
\hline CDVA & $20 / 20$ with $-1.0 \times 120$ degrees & $20 / 20$ with $-0.5-0.75 \times 95$ degrees \\
\hline \multicolumn{3}{|l|}{ Postoperative measurements at 12 months } \\
\hline Topcon KR8100 keratorefractometer & $\begin{array}{l}\text { K1: } 42.25 \mathrm{D} \\
\mathrm{K} 2: 46.25 \mathrm{D} \\
\mathrm{S}:-0.5 \mathrm{D} / \mathrm{C}:+1.0 \mathrm{D} / \mathrm{SE}: 0.0 \mathrm{D}\end{array}$ & $\begin{array}{l}\text { K1: } 48.0 \mathrm{D} \\
\text { K2: } 50.75 \mathrm{D} \\
\text { S: }-2.0 / \mathrm{C}:+0.75 \mathrm{D} / \mathrm{SE}:-1.75 \mathrm{D}\end{array}$ \\
\hline Pentacam HR & $\begin{array}{l}\mathrm{K} 1: 41.6 \mathrm{D} \\
\mathrm{K} 2: 45.4 \mathrm{D}\end{array}$ & $\begin{array}{l}\mathrm{K} 1: 47.7 \mathrm{D} \\
\mathrm{K} 2: 50.5 \mathrm{D}\end{array}$ \\
\hline UCDVA & $20 / 25$ & $20 / 20$ \\
\hline CDVA & $20 / 20$ with $-0.5 \times 115$ degrees & $20 / 20$ \\
\hline
\end{tabular}

Abbreviations: IOL intraocular lens, K1/K2 keratometry values for the steep and flat axis, $A L$ axial length, UCDVA uncorrected distance visual acuity, CDVA corrected distance visual acuity, AcrySof Toric SN6AT7, 4.5 D at IOL plane; AcrySof Toric SN6AT6, 3.75 D at IOL plane; S spherical (Diopter), C cylindric (Diopter), SE spherical equivalent (Diopter)

high astigmatism after posterior segment surgeries, due to scleral buckling or keratoconus. The patients underwent cataract extraction with toric IOL implantation. Both of the patients showed marked improvement in visual acuity and subjective refraction, while retinal pathologies remained stable. Therefore, phacoemulsification with toric IOL implantation seems to be an effective method for correcting high astigmatism in cataract patients after posterior segment surgeries and corneal pathologies.

Although there are several new effective techniques to correct astigmatism due to corneal ectasias, the correction of high astigmatism in cataract patients presenting with keratoconus continues to be challenging [3]. AcrySof toric IOL is considered to be one of the most commonly used toric IOL in cataract surgery with a handy and reliable online calculator. However, IOL power calculation is still a challenge in cataract patients with keratoconus [3]. Cataract surgery with implantation of toric IOL in stable keratoconus is a safe and effective procedure regarding keratometry stability, visual and refractive results [5]. The first result with toric IOL implantation after vitrectomy was reported in 2011, and showed that combined 
phacovitrectomy with toric IOL implantation is an effective method for correcting vitreoretinal diseases, cataract and pre-existing regular corneal astigmatism [1]. In vitrectomized eyes, the postoperative IOL axis stability for one year is similar to cataract surgery alone. Furthermore it has been proved that the vitrectomized status of eyes does not provoke mispositioning of toric IOL [2]. The similar incidence of rotation to the non-vitrectomized eyes may be derived from the special haptic design and adhesive properties of the AcrySof toric IOL [1, 2, 9]. Our keratoconus patient had cataract, which was induced by a previous vitrectomy. Since an accurate determination of $\mathrm{K}$ values and cylindrical axis is a prerequisite of a successful outcome, we used IOL Master and Pentacam HR for these measurements. These provided similar results including the cylindrical power of the toric IOL. To the best of our knowledge, there is no reported case of implantation a toric IOL in keratoconus after vitrectomy. Our results highlight that AcrySof toric IOL shows good rotational stability after vitrectomy, even in keratoconic eyes.

Scleral buckles indent the sclera, changing the sagittal dimensions of the globe and potentially causing corneal or fundus astigmatism [6-8]. In our patient, after scleral buckling surgery (encircling buckle and a radial sponge) we observed a myopic shift of $1.5 \mathrm{D}$, which is in-line with previous results $[6,8]$. Besides, we observed an unusually high corneal astigmatism of 3.5 D (Figs. 1 and 2). One month and also 12 months after toric IOL implantation, our patient was within the $\pm 0.5 \mathrm{D}$ of the planned correction. This result is better than those reported cohorts of patients after scleral buckling having corneal refractive surgery for correcting anisometropia [6]. Based on earlier studies, photorefractive keratectomy (PRK) seems to be more predictable in patients who have had previous scleral buckling surgery. However, the reason that the attempted result versus the achieved result is unfavorable in patients who have had refractive surgery after scleral buckling is unknown [6]. Calculating the cylindric power of the toric IOL the Pentacam HR and the IOL Master did not give similar results in our case, and we implanted the IOL correcting for the higher cylinder, measured by the Pentacam $\mathrm{HR}$ and the kerato-refractometer. The postoperative refractive results proved that this was a good decision. Further studies are needed to compare whether toric IOL implantation or corneal refractive surgery gives predictable results for anisometropia and astigmatism correction after scleral buckling surgery.

These cases demonstrate that toric IOL implantation may be safe and effective for the correction of refractive errors induced by retinal detachment repair or after vitrectomy in patients with corneal ectasia. The results of toric IOL implantation are always uncertain in previously

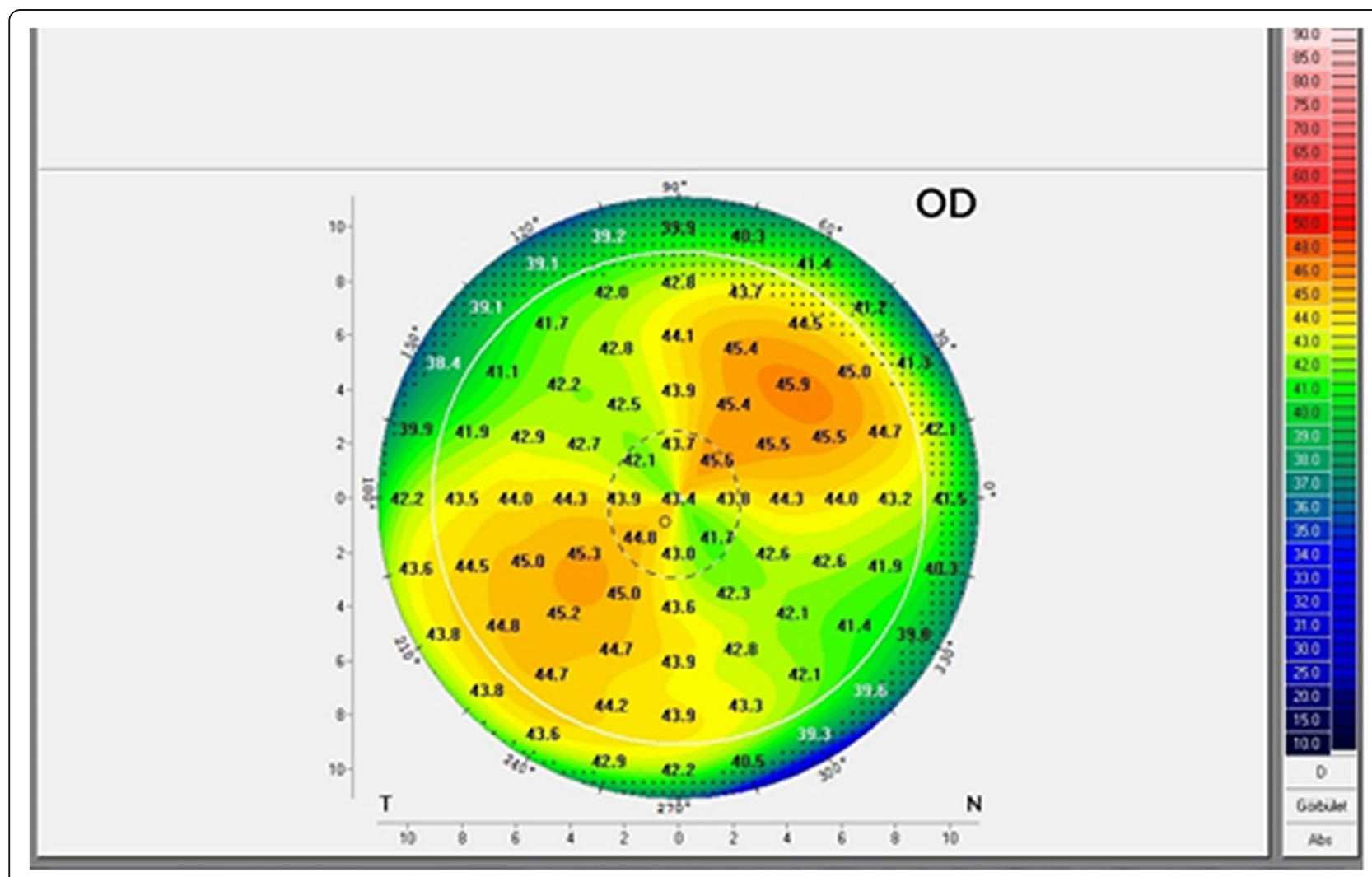

Fig. 1 Preoperative topography with Pentacam HR. High regular astigmatism is detected caused by a radial sponge 


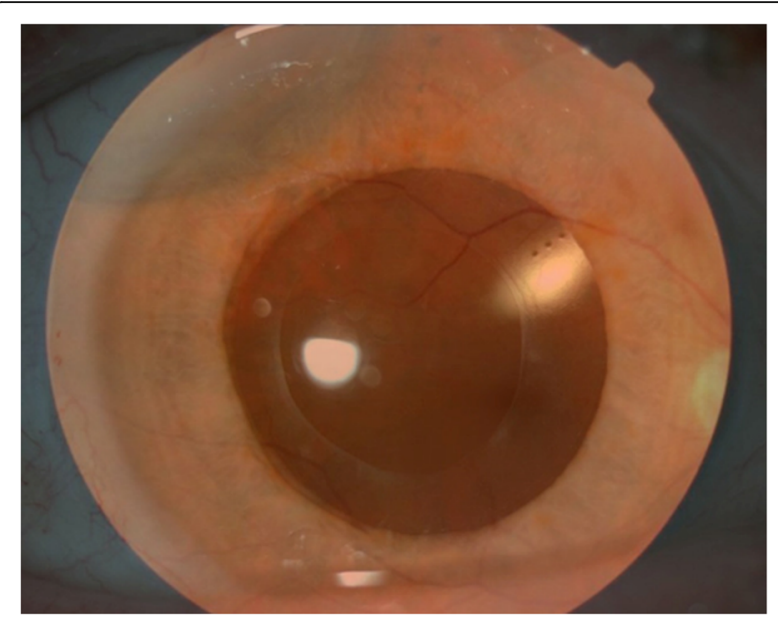

Fig. 2 Postoperative montage photo. Postoperative montage photo with toric IOL (see at 2 o'clock the cylinder axis marks on the posterior surface of the $\mathrm{IOL}$ ) and the superotemporal located radial sponge. The axis of the cylinder marks and the sponge is perpendicular

none published complicated cases. The report of such cases broadens the spectrum of conditions in which toric IOLs can be used with certainty. Both of our cases were complicated but the patients were well educated and agreed to implantation of the toric IOL, despite the previous vitreoretinal surgery. They were satisfied with the postoperative visual outcomes.

Our study has several limitations. Due to the limited number of cases and absence of previous reports, it is hard to precisely demonstrate the efficacy of toric IOL in vitrectomized, keratoconic eyes, as well as in eyes with induced astigmatism caused by scleral buckling implants. However, this study shows that AcrySof toric IOL has good rotational stability, achieving optimal refractive and visual outcomes, even in vitrectomized keratoconic eyes. This is also the case in eyes with induced astigmatism caused by scleral buckling implants, which has not been reported before. Additionally, Pentacam is considered to be an accurate tool for obtaining $K$ values and axis measurements, showing no differences compared with IOL Master in case of vitrectomized, keratoconic eyes. However, it could be said that Pentacam gives more precise calculation than IOL Master after scleral buckling surgery, and complimentary examinations are required for the decision (keratorefractometer, Orbscan).

In conclusion, after different types of posterior segment surgeries phacoemulsification with AcrySof, toric IOL implantation can be an effective method for correcting pre-existing irregular astigmatism resulting from ectatic corneal diseases, as well as surgically induced regular astigmatism. Further randomized and prospective studies with a larger study population are necessary to evaluate the efficacy, safety and predictability of toric
IOLs, and our study could be a useful reference for these future trials. The reconsideration of the contraindication for toric IOL implantation seems to be relevant. Most importantly, this is because the quality of life of these patients with complicated problems can improve dramatically with toric IOL implantation. We believe that our case series provides novel and valuable information on the treatment of extraordinary cases. Moreover, it seems unlikely that toric IOL implantation would increase the risk for retinal detachment or other vitreoretinal complications after previous retinal surgery (scleral buckling or vitrectomy).

\section{Abbreviations}

CDVA: Spectacle corrected distance visual acuity; D: Diopters; IOL: Intraocular lens; PRK: Photorefractive keratectomy; UCDVA: Uncorrected distance visual acuity

\section{Acknowledgements}

The authors thank the patients who generously agreed to participate in this medical report.

\section{Funding}

No funding was obtained for this study.

\section{Availability of data and materials}

All the data supporting the findings is contained within the manuscript.

\section{Authors' contributions}

BLK was a major contributor in writing the manuscript. BLK and DP contributed to the literature search and preparation of the manuscript and figures. GL and MF provided critical revision. MF was responsible for the clinical management of the patient and the design of the case report. All authors read and approved the final manuscript.

\section{Competing interests}

The authors declare that they have no competing interests.

\section{Consent for publication}

We confirmed that patients had seen the manuscript and patient data and agreed to its publication in a journal. Written informed consents were obtained from the patients for publication of this case report and any accompanying images. A copy of the consents is available for review by the Editor of this journal.

\section{Ethics approval and consent to participate}

Ethical approval was not required as this manuscript presents a case study. It was performed in accordance with the tenets of the Declaration of Helsinki. Following a comprehensive discussion of the toric IOL implantation and potential risks, both of the patients gave written consent.

Received: 21 July 2016 Accepted: 16 December 2016 Published online: 13 January 2017

\section{References}

1. Park DH, Shin JP, Kim SY. Combined 23-gauge microincisonal vitrectomy surgery and phacoemulsification with AcrySof toric intraocular lens implantation: a comparative study. Eye (Lond). 2011;25(10):1327-32.

2. Lee JY, Kang KM, Shin JP, Kim IT, Kim SY, Park DH. Two-year results of AcrySof toric intraocular lens implantation in patients with combined microincision vitrectomy surgery and phacoemulsification. Br J Ophthalmol. 2013:97(4):444-9.

3. Parikakis EA, Chatziralli IP, Peponis VG, David G, Chalkiadakis S, Mitropoulos PG. Toric intraocular lens implantation for correction of astigmatism in cataract patients with corneal ectasia. Case Rep Ophthalmol. 2013;4(3):219-28.

4. Visser N, Gast ST, Bauer NJ, Nuijts RM. Cataract surgery with toric intraocular lens implantation in keratoconus: a case report. Cornea. 2011;30(6):720-3. 
5. Alió JL, Peña-García P, Abdulla Guliyeva F, Soria FA, Zein G, Abu-Mustafa SK MICS with toric intraocular lenses in keratoconus: outcomes and predictability analysis of postoperative refraction. $\mathrm{Br} J$ Ophthalmol. 2014;98(3):365-70.

6. Holopainen JM, Vuori E, Moilanen JA, Zalentein WN, Tervo TM. Excimer laser refractive correction of myopia after episcleral buckling for rhegmatogenous retinal detachment. J Cataract Refract Surg. 2007;33(10):1744-9.

7. Leccisotti A. Phakic intraocular lenses after scleral buckling for retinal detachment. Eur J Ophthalmol. 2007;17(3):388-91.

8. Sforza PD, Saffra NA. Laser in situ keratomileusis as treatment for anisometropia after scleral buckling surgery. J Cataract Refract Surg. 2003; 29(5):1042-4.

9. Mendicute J, Irigoyen C, Aramberri J, Ondarra A, Montés-Micó R. Foldable toric intraocular lens for astigmatism correction in cataract patients. J Cataract Refract Surg. 2008;34(4):601-7.

Submit your next manuscript to BioMed Central and we will help you at every step:

- We accept pre-submission inquiries

- Our selector tool helps you to find the most relevant journal

- We provide round the clock customer support

- Convenient online submission

- Thorough peer review

- Inclusion in PubMed and all major indexing services

- Maximum visibility for your research

Submit your manuscript at www biomedcentral.com/submit 